\title{
Effect of fracture orientation on ultrasonic wave signatures
}

\author{
Bijay $\mathrm{KC}^{1, *}$ and Ehsan Ghazanfari ${ }^{1}$ \\ ${ }^{1}$ University of Vermont, Department of Civil and Environmental Engineering, 33 Colchester Ave, Burlington, VT, 05405
}

\begin{abstract}
Fluid flow through low-permeable rock masses is dominated by transport through discontinuities such as fractures, faults, and joints present in the rock. These discontinuities are beneficial for some georesources such as geothermal, oil and gas reservoir, but detrimental for other applications such as $\mathrm{CO}_{2}$ storage and hazardous waste isolation. Fracture orientation plays a critical role during the design of the geo-resources. Often times, ultrasonic waves are used in the field to locate and characterize the fractures. In this study, the effect of fracture orientation $\left(0^{\circ}\right.$ to $\left.90^{\circ}\right)$ on ultrasonic wave signatures was investigated by conducting a series of experiments on a granite rock with a longitudinal fracture under confining pressures of 15,30 , and $45 \mathrm{MPa}$. Ultrasonic wave signatures during the experiment were collected using the ultrasonic transducers embedded in the core holders that were attached to the two ends of the specimen. Results indicated sensitivity of the ultrasonic wave velocities, waveforms, and amplitudes (cross-polarized S-waves) to the fracture orientation.
\end{abstract}

\section{Introduction}

Geo-resources such as geothermal, shale gas/oil reservoir, $\mathrm{CO}_{2}$ sequestration site, nuclear waste repository, etc. involve bedrock with artificial (hydraulic fracturing) or natural fractures. Presence of such fractures (or faults) in the bedrock is beneficial in some geo-resources (i.e. geothermal and shale/oil reservoir) as it can be exploited to enhance the productivity of the reservoir. On the other hand, fractures (or faults) pose a serious environmental risk in the $\mathrm{CO}_{2}$ sequestration site and nuclear waste repository as they provide a leakage path for the waste contained within the reservoir. The physical properties of fracture such as orientation, asperities in contact, aperture size, etc. controls the mechanical and flow properties of the fracture. Identifying the location and physical characteristics of such fractures is crucial in assessment of the long-term performance of any geo-resources.

At laboratory scale, ultrasonic waves are shown to be sensitive to the different elements of geologic formations such as stress conditions, fluid saturations, internal structures of the intact rocks, and presence of fractures (or cluster of fractures) in the rock (e.g. [1-5]). Due to the lower cost, remote geophysical methods that use seismic waves are usually used in field (e.g. [6-7]) to measure the physical properties of fracture such as fluid flow, mechanical deformation, fracture geometry.

Fracture orientation controls the movement of the fluids within the reservoir. Therefore, knowledge about fracture orientation is crucial while drilling a well or enhancing the permeability of the reservoir using hydroshearing or hydraulic fracturing (e.g. [8-9]). The wave signals vary as a function of fracture orientation. Fracture reflects the wave if fracture dimensions are smaller to the wavelength and scatters the wave to form complex reverberating signature if the fracture dimensions are close in size to wavelength (e.g. [10-11]). Researchers have used $\mathrm{P}$-wave amplitude variation offset (AVO) (e.g. [12-14]) to characterize the fracture orientation. Shear wave splits into fast moving S1 wave that is parallel to the fracture plane and slow S2 wave, which is orthogonal to the fracture plane when it propagates through the fracture (e.g. [2, 15]). Cross-correlation between S1 and S2 wave can be used to estimate the fracture orientation [16].

Several experimental (e.g. $[4,17]$ ) as well as numerical (e.g. [14, 18]) studies have verified that the ultrasonic wave is affected by the presence of fracture in the rock. However, our understanding about the effect of fracture orientation on the wave is limited. In this study, a suite of laboratory-scale tests is conducted on a fractured crystalline rock at predetermined fracture orientations to investigate the effect of fracture orientation on the wave propagation characteristics of $\mathrm{P}$ and cross-polarized $\mathrm{S}$ ( $\mathrm{S} 1$ and S2) waves. Particularly, the impact of fracture orientation on wave velocities and waveforms is examined in this paper.

\section{Materials}

A rectangular block of granite specimen retrieved from the Rock of Ages quarry in Barre, Vermont was sub-cored to obtain a cylindrical specimen having a length of 37.5 $\mathrm{mm}$ and diameter of $38.5 \mathrm{~mm}$. The two ends of the cylindrical specimen were lapped to $0.025 \mathrm{~mm}$ to avoid non-uniform loading and local bending during the experiment. Modified Brazilian test was performed to induce an artificial longitudinal tensile fracture in the granite specimen (Fig. 1(a)).

\footnotetext{
* Corresponding author: $\underline{\text { bkc } @, \text { uvm.edu }}$
} 


\section{Experimental Methodology}

Autolab 1500, a high pressure/temperature fully servocontrolled triaxial equipment was used to examine the effect of fracture orientation on the ultrasonic wave signatures. The two halves of the fractured specimen were well mated and inserted in a Viton jacket. Then two core-holders, which contain ultrasonic transducers, were wire-tightened to the two ends of the specimen (Fig. 1(b)). The fracture plane was manually oriented at different angles (within an error of $\pm 5^{\circ}$ ) with respect to the plane of propagation of the waves.

The ultrasonic transducers inside the bottom coreholder emit the $\mathrm{P}$ and cross-polarized S-waves, which direction of the propagation $[4,14,15]$ (Fig. 2(a)). Shear waves or S-waves propagate by moving the rock particles side-to-side, or up and down perpendicular to the wave propagation direction (Fig 2(b)). Based on the movement of the particles, i.e. side-to-side or up and down, two shear waves faster S1 and slower S2 can propagate through the rock specimen. S1-wave is the fast velocity mode, which is polarized in the same direction as the fracture orientation, i.e. fracture orientation is $0^{\circ}$ with respect to the plane of wave propagation (green wave in Fig. 2(b)). $\mathrm{S} 2$-wave is polarized in the direction orthogonal to the fracture plane, i.e. fracture orientation is $90^{\circ}$ with respect to the plane of wave propagation $[5,15,16]$ (red wave in

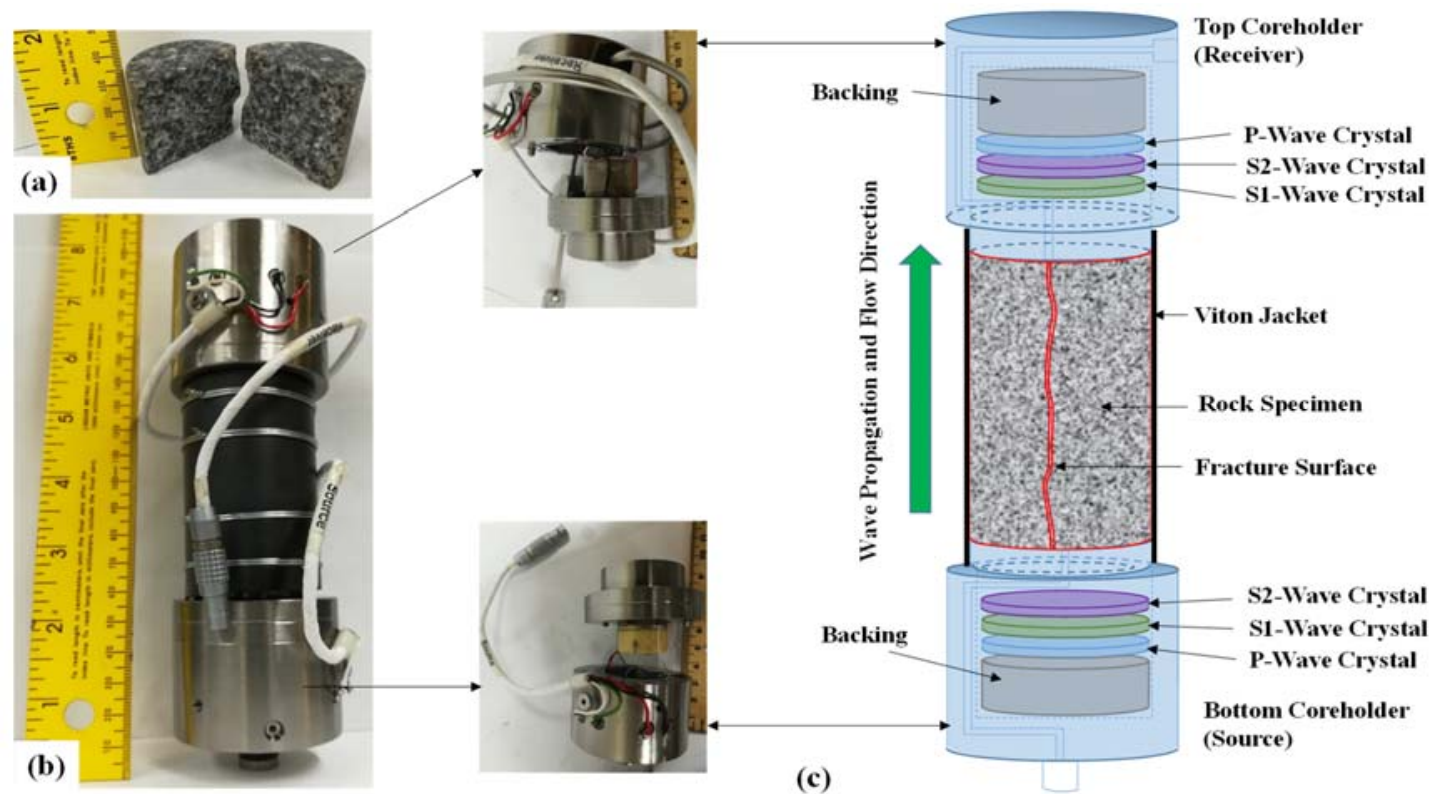

Fig. 1. Photo of (a) fractured granite specimen, (b) specimen wire-tightened to the two core-holders on both ends, and (c) schematics of the ultrasonic wave transducers inside the core-holder.

propagate through the fractured rock specimen before being received by the transducers inside the top coreholders. As shown in Fig. 1(c), the $\mathrm{P}$ and S-waves transducers are stacked together inside the core-holders. The $\mathrm{P}$ and $\mathrm{S}$-waves transducers have a diameter of $22 \mathrm{~mm}$ and thickness of 2 and $1 \mathrm{~mm}$, respectively. The transducers are made up of PZT5A, a polarized ceramic type lead-zirconate-titanium alloy. The crystalline structure of this material enables sending the ultrasonic waves in a particular direction. The transducers were set to the central frequency of $750 \mathrm{KHz}$ with a pulse generation and acquisition rate of 10 pulses/second. Tektronix TDS 3000 Series Oscilloscope equipped within the Autolab 1500 was used as a digitizer during the experiment. $\mathrm{P}$ and $\mathrm{S}$-waves velocities were estimated using manually picked arrival time of the waves according to ASTM D5777 Standard [19].

\section{Results and Discussions}

P-wave is the fastest wave, which propagates by creating alternate zones of compression and rarefaction along the
Fig. 2(b)). The fracture orientation was measured with respect to the plane of propagation of S1 wave.

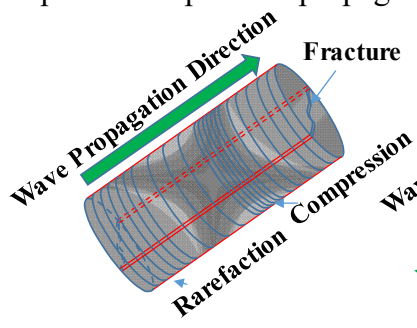

(a)

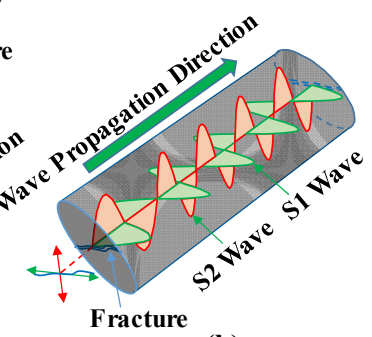

(b)
Fig. 2. Schematics showing the propagation of (a) compressional P wave and (b) cross-polarized shear (S1 and S2) waves in the fractured specimen.

Experiments were performed on an intact and jointed aluminum of same dimension $(\mathrm{L}=47.0 \mathrm{~mm}$ and $\mathrm{d}=38.1$ $\mathrm{mm}$ ) at different fracture plane orientations to confirm the measured variation in the received wave is due to the presence of the fracture and not an artifact measured by transducers' error. Fig. 3 shows the P, S1, and S2 waveforms at the mean total stress of $15 \mathrm{MPa}$ for intact 
and jointed aluminum with the joint plane oriented at $0^{\circ}$ and $45^{\circ}$ with respect to the $\mathrm{S} 1$ wave propagation plane. $\mathrm{P}$ wave velocity and received waveform remained unaffected by the presence of the fracture. However, maximum amplitude of $\mathrm{P}$ wave increased in a jointed specimen. S1 and S2 wave velocities and the maximum amplitude of the received wave decreased with the introduction of the fracture. Moreover, the received S1 and $\mathrm{S} 2$ waveforms of the jointed aluminum specimen are different for the fracture orientation of $0^{\circ}$ and $45^{\circ}$. This confirms the measured variation in the waves is due to the fracture and not and artifact measured by transducers' error.

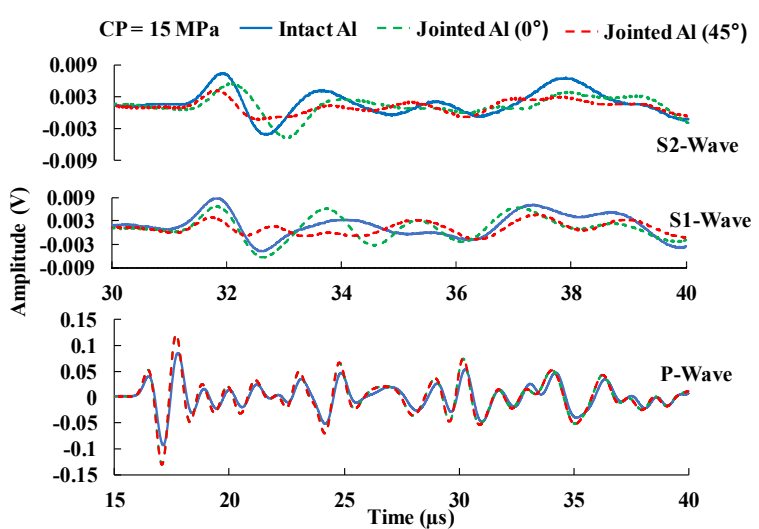

Fig. 3. Ultrasonic wave signatures after propagating through intact and jointed aluminum at $0^{\circ}$ and $45^{\circ}$.
$\mathrm{P}, \mathrm{S} 1$, and S2 waves were transmitted through the granite specimen having a longitudinal fracture at mean total stresses of 15,30 and $45 \mathrm{MPa}$, and fracture orientation angles of $0^{\circ}, 45^{\circ}$ and $90^{\circ}$. The P-waveform received on the receiver end remained unaffected with respect to the fracture orientation angle. However, the Pwave velocity increased with the mean total stress. Studies have shown that the presence of a fracture orthogonal to the propagation direction of the P-wave reduces the wave velocity, attenuates the wave, and reduces the high frequency content of the signal (e.g. [17, 20]). In this study, the fracture surface was parallel to the propagation direction and well mated. P-wave propagating parallel to the fracture makes a zone of compression and rarefaction on both halves of the fractured specimen. Since the wave propagated from one end to the other end, the $\mathrm{P}$ wave is incident parallel to the fracture plane at all fracture orientations. Therefore, the $\mathrm{P}$ waveforms did not exhibit any change with respect to the fracture orientation. However, as the mean total stress increased, the fracture closed due to crushing of the asperities, which increases the fracture specific stiffness of the rock specimen [4]. Therefore, the P wave velocity increased with the mean total stress.

Fig. 4 compares the received $\mathrm{S} 1$ and $\mathrm{S} 2$ wave at fracture orientations of $0^{\circ}, 45^{\circ}$, and $90^{\circ}$. At fracture orientation of $0^{\circ}, \mathrm{S} 1$ wave arrives earlier with the amplitudes greater than S2 wave (Fig. 4(a)-(c)). The arrival time and amplitudes of $\mathrm{S} 1$ and $\mathrm{S} 2$-waves are

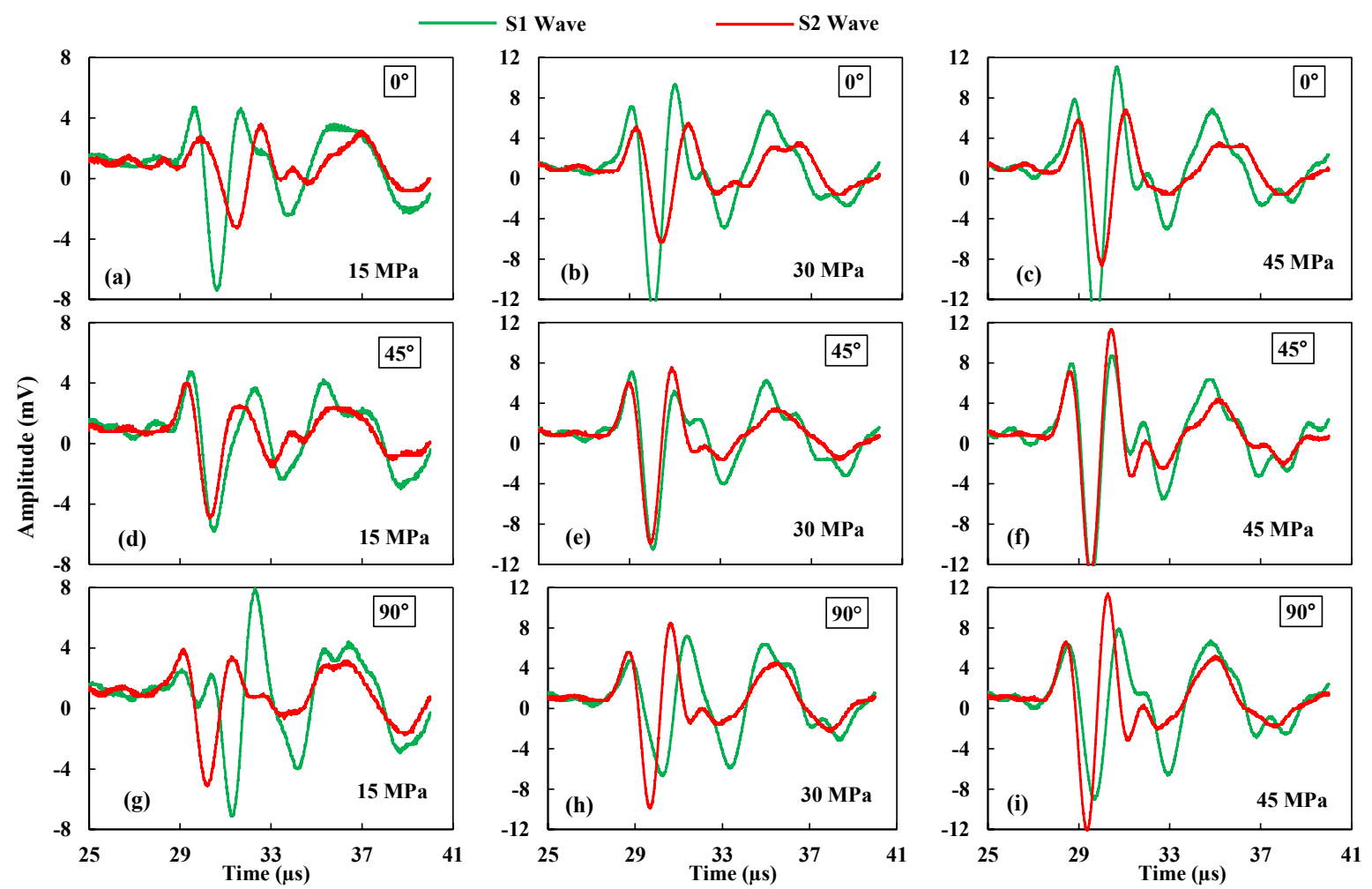

Fig. 4. Received S1 and S2 waveform at fracture orientation of $0^{\circ}$ and mean total stress of (a) $15 \mathrm{MPa}$, (b) $30 \mathrm{MPa}$ and (c) $45 \mathrm{MPa}$, fracture orientation of $45^{\circ}$ and mean total stress of (d) $15 \mathrm{MPa}$, (e) $30 \mathrm{MPa}$ and (f) $45 \mathrm{MPa}$, and fracture orientation of $90^{\circ}$ and mean total stress of (g) $15 \mathrm{MPa}$, (h) $30 \mathrm{MPa}$ and (i) $45 \mathrm{MPa}$. 

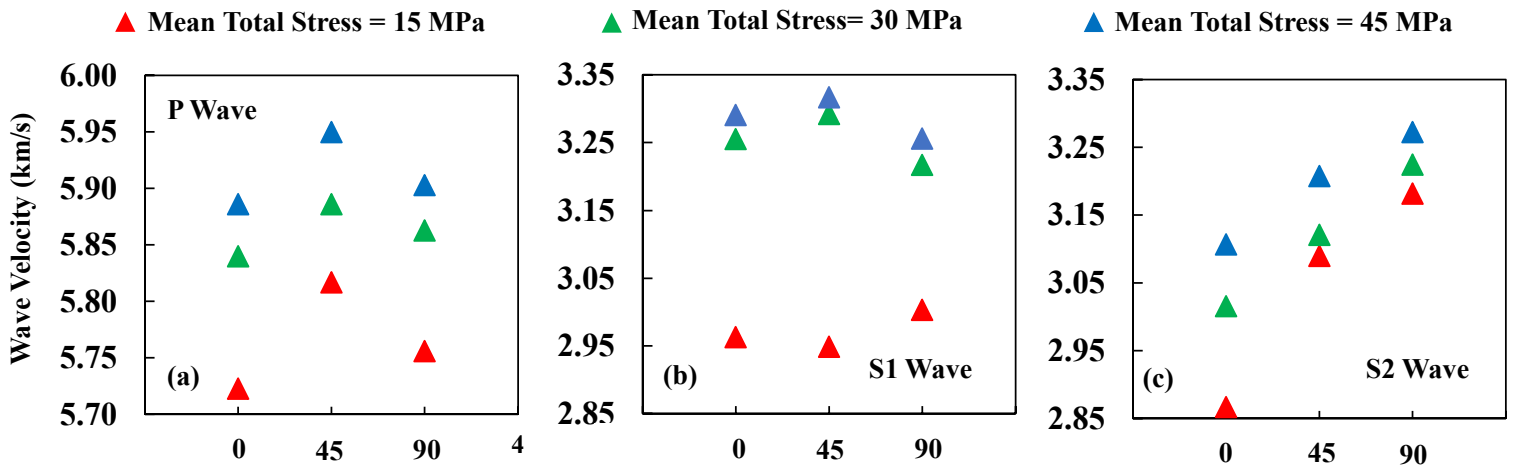

Fracture Orientation Angle ( ${ }^{\circ}$ )

Fig. 5. Variation in (a) $\mathrm{P}$ wave, (b) S1 wave, and (c) S2 wave velocities with respect to fracture orientation angle at different mean total stress levels.

comparable with each other when the fracture orientation is $45^{\circ}$ (Fig. 4(d)-(f)). S2 wave arrived earlier with higher amplitude values than $\mathrm{S} 1$ wave in case of $90^{\circ}$ fracture orientation (Fig. 4(g)-(i)).

When the fracture orientation is $0^{\circ}$, plane of polarization of S1 wave is parallel to the fracture plane. On the other hand, at $90^{\circ}$ fracture orientation, the plane of polarization of S2 wave becomes parallel to the fracture plane. This explains the shorter arrival time of S1 wave at fracture orientation of $0^{\circ}$ and S2 wave at $90^{\circ}$ fracture orientation. Plane of polarization of both $\mathrm{S} 1$ and $\mathrm{S} 2$ waves makes $45^{\circ}$ angle with the fracture plane when it is oriented at $45^{\circ}$. Hence, both S1 and S2 waves have same arrival time and waveform. Wave loses energy due to reflection, when it propagates through the fracture (e.g. [21-22]). S2 wave at the fracture orientation of $0^{\circ}$ and $\mathrm{S} 1$ wave at the fracture orientation of $90^{\circ}$ have the polarization plane orthogonal to the fracture plane. Hence, some of the energy carried by the wave is reflected when the wave propagates across the fracture. Lower amplitude observed for S2 and S1 wave at fracture orientation of $0^{\circ}$ and $90^{\circ}$, respectively could be attributed to the reflection of the energy due to the presence of the fracture across the propagation path of the waves.

P-wave and S1 wave velocities were observed to be maximum when the fracture orientation was $45^{\circ}$ (except S1 wave velocity at $15 \mathrm{MPa}$ ) (Fig. 5(a) \& (b)). S2 wave velocity increased with increased fractured orientation angle (Fig. 5(c)). At a fracture orientation of $90^{\circ}, \mathrm{S} 1$ wave has the particle displacement plane orthogonal to fracture plane, whereas S2 wave has the particle displacement plane parallel to fracture plane, in other words, S1 and S2 waves change their properties compared to those at fracture orientation of $0^{\circ}$. Energy carried by the waves gets reflected (or scattered by asperities) when the fracture orientation is $0^{\circ}$ and $90^{\circ}$ for $\mathrm{S} 2$ and $\mathrm{S} 1$ waves, respectively (e.g. [21-22]). Thus, S1 waves exhibited higher velocities than S2 waves at the fracture orientation of $0^{\circ}$ and viceversa at fracture orientation of $90^{\circ}$ for all mean total stresses, except in the case of $30 \mathrm{MPa}$ where S1 and S2 wave velocities are almost equal at $90^{\circ}$ orientation (Fig. $5(\mathrm{~b}) \&(\mathrm{c}))$.

Both, P-wave and cross-polarized $\mathrm{S}$ waves velocities increased with the mean total stress (Fig. 5). As the mean total stress increases, two halves of the specimen move further closer to each other, which decreases the fracture aperture (i.e. increases fracture specific stiffness) and consequently the velocity increases with the mean total stress (e.g. [23 - 25]). Crystalline granite rock with very low matrix porosity $(0.72 \%)$ and high compressive strength was used in the study. The change in the overall length of the specimen was negligible under the maximum mean total stress of $45 \mathrm{MPa}$. Hence, the wave velocities reported in this paper were not corrected for the specimen shortening.

\section{Conclusion}

Effect of the fracture orientation on the ultrasonic wave properties (especially velocity and waveform) was investigated by propagating an ultrasonic P, S1 and S2 waves through a granite specimen having an artificially induced longitudinal fracture. Three different fracture orientations of $0^{\circ}, 45^{\circ}$, and $90^{\circ}$ were investigated each under the mean total stress of 15,30 and $45 \mathrm{MPa}$. Although the P-wave waveform did not show any significant change, P-wave velocity was observed to be maximum at the fracture orientation of $45^{\circ}$. Crosspolarized S-waves (S1 and S2) were sensitive to the fracture orientation. P-wave along with the S1 and S2 wave velocities increased with the stress level because of the closure of the fracture under higher stresses.

Fracture orientation is a crucial parameter in reservoir design as it controls the fluid movement within the reservoir. Remote geophysical methods such as ultrasonic waves can be used in the field to characterize the fracture (or fault) orientation. Reflection, scattering, or dispersion of the wave due to the fracture also affects the attenuation and frequency content of the wave. Authors would like to acknowledge that investigating these properties could provide important insights about the effect of fracture orientation on wave properties. Rock dominated with fracture network is more realistic scenario in the field. Therefore, investigating the impact of fracture network on ultrasonic waves could provide more insights useful for reservoir design and management. 


\section{References}

1. K. Amalokwu, A.I. Best, J. Sothcott, M. Chapman, T. Minshull, \& X.Y. Li, Water Saturation Effects on Elastic Wave Attenuation in Porous Rocks with Aligned Fractures. Geophysical Journal International, 197(2), 943-947 (2014).

2. K. Amalokwu, M. Chapman, A.I. Best, J. Sothcott, T.A. Minshull, \& X.Y. Li, Experimental Observation of Water Saturation Effects on Shear Wave Splitting in Synthetic Rock with Fractures Aligned at Oblique Angles. Geophysical Journal International, 200(1), 17-24 (2015).

3. A. Kamali-Asl, B. KC, E. Ghazanfari, \& A. Hedayat, Flow-Induced Alterations of Ultrasonic Signatures and Fracture Aperture Under Constant State of Stress in a Single-Fractured Rock. Geophysics, 84(4), WA115-WA125 (2019).

4. A. Kamali-Asl, B. Kc, M. Foroutan, E. Ghazanfari, T.T. Cladouhos, \& M. Stevens, Stress-Strain Response and Seismic Signature Analysis of Phyllite Reservoir Rocks from Blue Mountain Geothermal Field. Geothermics, 77, 204-223 (2019).

5. D. Katsuki, M. Gutierrez, \& A. Almrabat, StressDependent Shear Wave Splitting and Permeability in Fractured Porous Rock. Journal of Rock Mechanics and Geotechnical Engineering, 11(1), 1-11 (2019).

6. M. Aleardi, \& A. Mazzotti, A Feasibility Study on the Expected Seismic AVA Signatures of Deep Fractured Geothermal Reservoirs in an Intrusive Basement. Journal of Geophysics and Engineering, 11(6), 065008 (2014).

7. T.A. Taira, A. Nayak, F. Brenguier, \& M. Manga, Monitoring Reservoir Response to Earthquakes and Fluid Extraction, Salton Sea Geothermal Field, California. Science Advances, 4(1), e1701536 (2018).

8. M.W. McClure, \& R.N. Horne, An Investigation of Stimulation Mechanisms in Enhanced Geothermal Systems. International Journal of Rock Mechanics and Mining Sciences, 72, 242-260 (2014).

9. A. Finnila, W. Dershowitz, T. Doe, \& R. McLaren, Hydro-Shearing and Hydraulic Fracturing for Enhanced Geothermal Systems in Archetypical Normal, Strike-Slip, and Thrust Faulting Terrains. GRC Trans, 39, 1-19 (2015).

10. M.E. Willis, D.R. Burns, R. Rao, B. Minsley, M.N. Toksöz, \& L. Vetri, Spatial Orientation and Distribution of Reservoir Fractures from Scattered Seismic Energy. Geophysics, 71(5), O43-O51 (2006).

11. X. Fang, M. Fehler, T. Chen, D. Burns, \& Z. Zhu, Sensitivity Analysis of Fracture Scattering. Geophysics, 78(1), T1-T10 (2013).

12. S. Mallick, K.L. Craft, L.J. Meister, \& R.E. Chambers, Determination of The Principal Directions of Azimuthal Anisotropy From P-Wave Seismic Data. Geophysics, 63(2), 692-706 (1998).

13. C.M. Sayers, Seismic Characterization of Reservoirs Containing Multiple Fracture Sets. Geophysical prospecting, 57(2), 187-192 (2009).
14. M.E. Far, C.M. Sayers, L. Thomsen, D.H. Han, \& J.P. Castagna, Seismic Characterization of Naturally Fractured Reservoirs Using Amplitude Versus Offset and Azimuth Analysis. Geophysical Prospecting, 61, 427-447 (2013).

15. P. Tillotson, J. Sothcott, A.I. Best, M. Chapman, \& X.Y. Li, Experimental Verification of The Fracture Density and Shear-Wave Splitting Relationship Using Synthetic Silica Cemented Sandstones with a Controlled Fracture Geometry. Geophysical Prospecting, 60(3), 516-525 (2012).

16. J.J.S De Figueiredo, J. Schleicher, R.R Stewart, \& N. Dyaur, Estimating Fracture Orientation from ElasticWave Propagation: An Ultrasonic Experimental Approach. Journal of Geophysical Research: Solid Earth, 117(B8) (2012).

17. L.J. Pyrak-Nolte, The Seismic Response of Fractures and The Interrelations Among Fracture Properties. International journal of rock mechanics and mining sciences \& geomechanics abstracts, 33(8), 787-802 (1996).

18. M.A. Schoenberg, S. Dean, \& C.M. Sayers, AzimuthDependent Tuning of Seismic Waves Reflected from Fractured Reservoirs. Geophysics, 64(4), 1160-1171 (1999).

19. A. S. T. M. D5777-00, Standard Guide for Using the Seismic Refraction Method for Subsurface Investigation: ASTM International (2011)

20. J. Zhao, \& J.G. Cai, Transmission of Elastic P-Waves Across Single Fractures with A Nonlinear Normal Deformational Behavior. Rock Mechanics and Rock Engineering, 34(1), 3-22 (2001).

21. L.J. Pyrak-Nolte, L.R. Myer, \& N.G. Cook, Transmission of Seismic Waves Across Single Natural Fractures. Journal of Geophysical Research: Solid Earth, 95(B6), 8617-8638 (1990).

22. F.K. Boadu, \& L.T. Long, Effects of Fractures on Seismic-Wave Velocity and Attenuation. Geophysical Journal International, 127(1), 86-110 (1996).

23. Holt, R. M., Nes, O. M., \& Fjaer, E, In-situ Stress Dependence of Wave Velocities in Reservoir and Overburden Rocks. The Leading Edge, 24(12), 1268-1274, (2005).

24. KC, B., Kamali-Asl, A., \& Ghazanfari, E., Seismic Signatures as a Proxy for Fracture Aperture Alterations in Reservoir Rock. In AGU Fall Meeting Abstracts, (2018, December).

25. Kamali-Asl, A., Ghazanfari, E., Perdrial, N., \& Cladouhos, T., Effects of Injection Fluid Type on Pressure-Dependent Permeability Evolution of Fractured Rocks in Geothermal Reservoirs: An Experimental Chemo-mechanical Study. Geothermics, 87, 101832, (2020). 